\title{
Adrenocortical hyporesponsiveness after treatment with ACTH of infantile spasms
}

\author{
J PERHEENTUPA, R RIIKONEN, L DUNKEL, AND O SIMELL \\ Children's Hospital, University of Helsinki, Helsinki, Finland
}

SUMMARY The hypothalamic-pituitary-adrenocortical axis was studied in 10 infants before and during a six week period of treatment with adrenocorticotrophic hormone (ACTH) and three days and one and two weeks after its stopping. During the treatment 24 hour urinary cortisol excretion increased 20 to 350 -fold (mean 100) above the basal value. Mean morning serum cortisol concentration, measured 24 hours after the preceding ACTH dose, did not increase. After the treatment mean urinary cortisol excretion was subnormal and mean morning serum cortisol concentration was below the pretreatment value. The mean serum cortisol response to a vasopressin test was reduced and shortened throughout the post-treatment observation period. The mean serum cortisol response to an intravenous ACTH test was not significantly different from the pretreatment response three days after treatment but was clearly reduced thereafter. At one and two weeks after treatment the basal concentrations of serum cortisol of one third of the patients and the post-ACTH concentrations of two thirds were subnormal. We conclude that in infants treatment with ACTH may cause adrenocortical hyporesponsiveness.

Treatment with adrenocorticotrophic hormone (ACTH) is believed to suppress the hypothalamicpituitary-adrenocortical axis far less than treatment with pharmacologic glucocorticoid. ${ }^{1}$ Serum cortisol responses to vasopressin test are often abnormal during treatment with $\mathrm{ACTH},{ }^{2-4}$ but impaired adrenocortical responsiveness to ACTH has not been reported after such treatment. A high dose course of ACTH lasting several weeks is commonly given to infants suffering from infantile spasms. ${ }^{5}$ Complications, even fatal ones, are common after such treatment. ${ }^{6}$ We assessed the state of the hypothalamic-pituitary-adrenocortical axis before and after such treatment and found reduced adrenocortical responsiveness to ACTH.

\section{Patients and methods}

Our series comprised 10 infants admitted to this hospital over a 24 month period for infantile spasms. Their ages on admission were 5-22 (mean 9) months and their weights $6 \cdot 1-12 \cdot 2(8 \cdot 9) \mathrm{kg}$. Long acting carboxymethyl-cellulose ACTH (Acortan prolongatum, Ferring, Malmö, Sweden) was given intramuscularly every morning, 80 IU (6.6 to $13 \cdot 1$, mean $9 \cdot 5$ IU/kg) during weeks $1-3$ and $40 \mathrm{IU}$ during weeks 4 and 5, with tapering during and stopping at the end of week 6. Blood samples were drawn at $0800 \mathrm{~h}$ (before injection of ACTH) and 24 hour urine samples collected before the start of treatment, at two days and one, three, five, and six weeks of treatment, and at three days and one and two weeks after treatment.

The hypothalamic-pituitary-adrenocortical axis was studied by a combined vasopressin-ACTH test (starting at 0910h before injection of ACTH) before treatment and three days and one and two weeks after the stopping of treatment. Aqueous lysine vasopressin (Sandoz, Basel, Switzerland) $10 \mathrm{IU} / \mathrm{m}^{2}$ was given intramuscularly at time 0 and tetracosactide (Organon, Oss, The Netherlands) $0.15 \mathrm{mg} / \mathrm{m}^{2}$ intravenously at 60 minutes. Cutaneous vasoconstriction and slight flaccidity occurred within five minutes after the vasopressin injection; these subsided within 10-30 minutes. Concentrations of cortisol were measured from serum samples obtained at $0,30,60,120$, and 180 minutes. $^{7}$ Our reference serum cortisol values were $\geqslant 230 \mathrm{nmol} / \mathrm{l}$ for the basal concentration, $>660 \mathrm{nmol} / \mathrm{l}$ for the highest concentration (post-vasopressin) at 30 to 60 minutes, and $\geqslant 820 \mathrm{nmol} / \mathrm{l}$ for the concentration at 180 minutes (two hours after ACTH). ${ }^{8}$

Serum and free urine cortisol were measured by radioimmunoassay (cortisol- ${ }^{-125}$ I radioimmunoassay 
kit, Farmos Diagnostica, Turku, Finland). ${ }^{7}$ As the distribution of the individual values was positively skewed calculations were performed on log transformed data and geometric means and mean (SEM) intervals are presented throughout. We used the $t$ test for paired data and standard methods for correlation coefficients. ${ }^{9}$

\section{Results}

Twenty four hour urinary cortisol excretion increased massively to a mean that was 100 times greater than the mean pretreatment excretion of 6.5 $\mathrm{nmol} / \mathrm{kg}$ (Fig. 1). The mean morning serum cortisol concentrations, measured 24 hours after the preceding ACTH dose, did not increase significantly (Fig. 1). The individual values, however, showed a positive correlation with the relative dose of ACTH (IU/kg; this was inversely dependent on body weight $)$ at two days $(r=0.84, p<0.01)$ and one week of treatment $(r=0.76, p<0.01)$. After the treatment the mean 24 hour urinary cortisol excretion fell abruptly to subnormal concentrations, $0.35 \mathrm{nmol} / \mathrm{kg}$ at one week and $0.78 \mathrm{nmol} / \mathrm{kg}$ at two weeks. The mean post-treatment serum cortisol concentrations were also significantly below the mean pretreatment concentrations. At one week after treatment the degree of this suppression showed an inverse correlation with the relative $\mathrm{ACTH}$ dose $(\mathrm{r}=-0.71, \mathrm{p}<0.05)$.

In all infants the results of the vasopressin-ACTH test were normal before treatment (Fig. 2). After treatment the mean maximal serum cortisol concentration in the vasopressin test was markedly reduced, with no sign of recovery by two weeks. In the ACTH test three days after treatment the mean 60 minute post-ACTH serum cortisol concentration was normal and similar to the pretreatment value. The response was abnormally short, however, and by 120 minutes post-ACTH the mean serum cortisol concentration had already decreased significantly. Of the individual infants, subnormal values occurred basally in five of the nine infants studied, at post-vasopressin maximum in two of nine, and at two hours post-ACTH in one of six. At one and two weeks after treatment even the mean 60 minute post-ACTH serum cortisol concentration was markedly reduced, indicating diminished adrenocortical responsiveness to direct stimulation. Of the individual infants at one week after treatment subnormal values occurred basally in three of six, at post-vasopressin maximum in one of six, and at two hours post-ACTH in two of four. At two weeks after treatment these numbers were two of eight, two of eight, and five of seven, respectively. A negative correlation $(r=-0.80, p<0.01)$ was found between
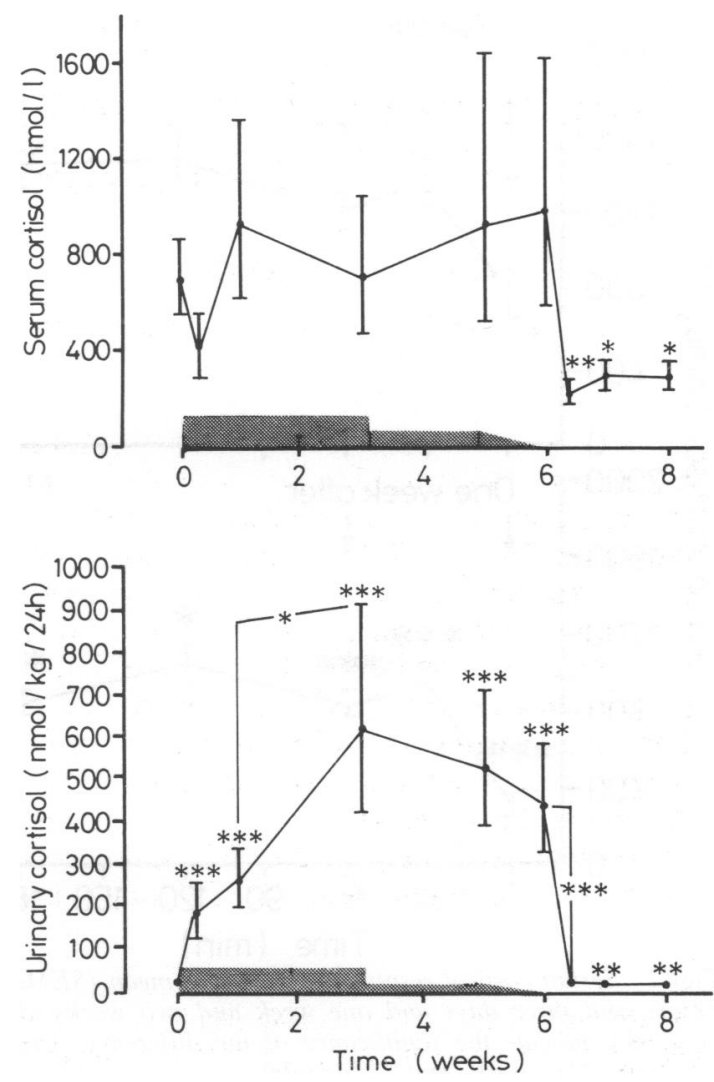

Fig. 1 Morning serum cortisol concentrations (upper panel) (geometric mean (SEM)) and 24 hour urinary cortisol excretion (lower panel) in 10 infants during and after treatment with carboxymethyl cellulose adrenocorticotrophic hormone (ACTH). Asterisks indicate the significance of the differences from the basal concentrations; ${ }^{*} p<0.05,{ }^{* *} p<0.01$, and ${ }^{* * *} p<0.001$. Dosage of $A C T H$ is indicated by the hatched area.

Conversion: SI to traditional units-Cortisol: $1 \mathrm{nmol}=0 \cdot 363 \mu \mathrm{g}$.

the highest post-ACTH plasma cortisol concentration at two weeks post-treatment and the maximum 24 hour urinary cortisol excretion during treatment.

\section{Discussion}

Treatment with ACTH has been advocated as a preferable alternative to treatment with pharmacologic glucocorticoid because of its less suppressive effect on the hypothalamic-pituitary-adrenocortical axis. ${ }^{1}$ It has not been seen as reducing the capacity of the adrenal cortex to respond to ACTH, although reduced morning serum cortisol concentrations have 


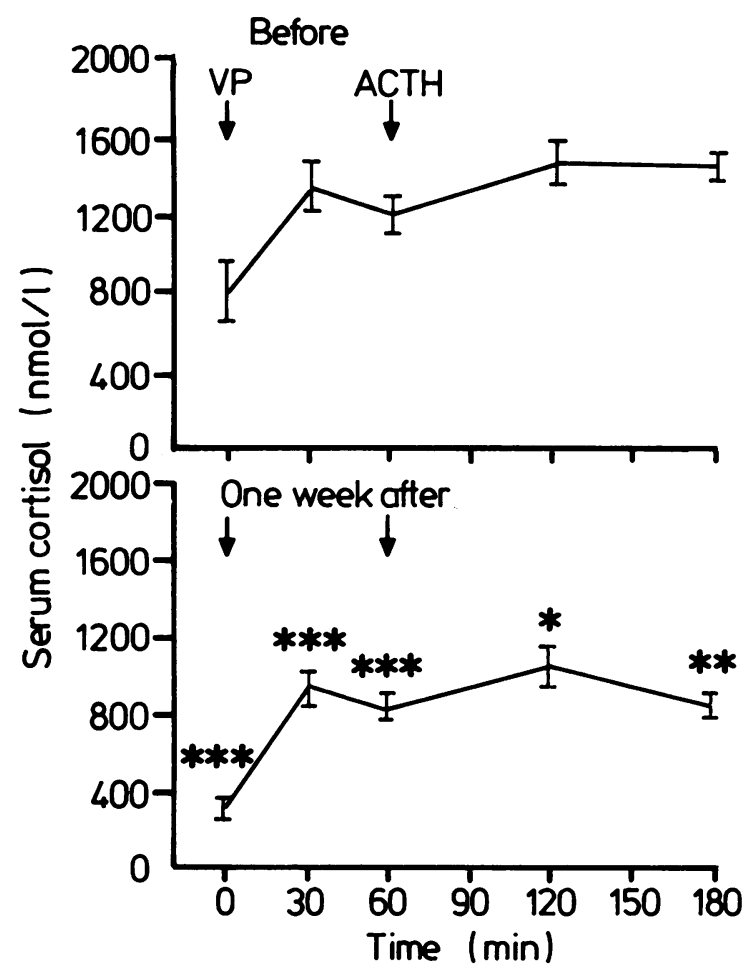

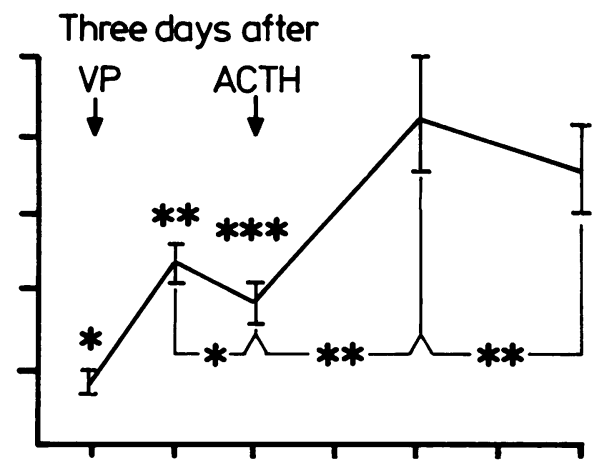

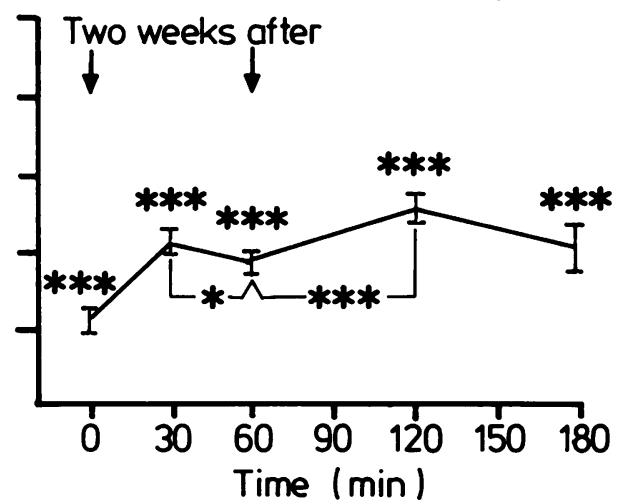

Fig. 2 Serum cortisol responses (geometric mean (SEM)) to combined vasopressin (VP) and ACTH test in 10 infants before and three days and one week and two weeks after treatment with adrenocorticotrophic hormone (ACTH). Asterisks indicate the significance of the differences from the pretreatment value at the corresponding time point; ${ }^{*} p<0.05,{ }^{* *} p<0 \cdot 01$, and ${ }^{* * *} p<0.001$.

Conversion: SI to traditional units-Cortisol: $1 \mathrm{nmol}=0 \cdot 363 \mu \mathrm{g}$.

been reported after treatment with $\mathrm{ACTH}{ }^{10} 11$ and serum cortisol responses in the vasopressin test have often been subnormal. ${ }^{2-4}$ Serum cortisol responses to insulin hypoglycaemia, however, have been normal, ${ }^{312} 13$ and this has been accepted as indicating a safe capacity for responding to stress.

During prolonged treatment with ACTH the adrenal zona fasciculata becomes hypertrophied. Consequently, response to an ACTH stimulation test in cortisol secretion is supranormal. At the same time release of $\mathrm{ACTH}$ in response to different stimuli is expected to be reduced. Accordingly, in the present study the serum cortisol response to vasopressin stimulation remained subnormal in extent and duration throughout our two week posttreatment observation period. The mean serum cortisol response to direct stimulation of the adrenal cortex with a standard two hour ACTH test three days after treatment was normal 60 minutes postACTH. However, by 120 minutes post-ACTH the mean serum cortisol concentration had already decreased, in contrast to the concentration noted in tests on normal children. ${ }^{8}$ At one and two weeks after treatment the mean serum cortisol response was markedly reduced even at 60 minutes postACTH, and most individual infants had subnormal responses. At two weeks the highest stimulated concentration was inversely proportional to the maximal cortisoluria during treatment. It seems that in these infants the hypercortisolism during treatment with ACTH suppresses secretion of ACTH enough to cause rapid involution of the adrenal cortex after stopping treatment with reduced ability to respond to ACTH stimulation. Another possible mechanism underlying the adrenocortical hyporesponsiveness could be desensitisation of the response effector mechanism. This seems less likely because it would be expected to peak during the height of the ACTH stimulation rather than after it as clearly happened.

In view of this subnormal response to stress some infants at least will probably be at considerable risk. 
We do not know whether further impairment occurs before recovery.

The ACTH preparation that was used had only a slightly prolonged action. In most of the infants serum cortisol concentrations were no longer raised 24 hours after the intramuscular injection. Preparations with $\mathrm{Zn}$-(more) prolonged action would probably cause an even more pronounced post-treatment involution of the adrenal cortex.

From the evidence available it seems that in children the hypothalamic-pituitary-adrenocortical axis is more sensitive to suppression by treatment with pharmacological glucocorticoid than it is in adults. ${ }^{14}$ Whether this is also true of suppression by treatment with ACTH remains unknown. In any case prolonged treatment with ACTH should not be stopped abruptly. Patients undergoing such treatment should be tested for possible hypoadrenocorticism and provided with appropriate cortisol substitution until full recovery is confirmed.

This study was supported by the Research Department, Rinnekoti Foundation, Finland, and the Foundation for Paediatric Research, Finland. We thank Ms Marjatta Viikari for skilful technical help.

\section{References}

${ }^{1}$ Myles AB, Daly JR. Corticosteroid and ACTH treatment. Principles and problems. London: Edward Arnold, 1974:170-2.

2 Bacon PA, Daly JR, Myles AB, Savage O. Hypothalamopituitary adrenal function in patients on long term adrenocorticotrophin therapy. Ann Rheum Dis 1968;27:7-13.

${ }^{3}$ Carter ME, James VH. Effect of corticotrophin therapy on pituitary-adrenal function. Ann Rheum Dis 1970;29:73-80.

${ }^{4}$ Levell MJ, Stitch SR, Noronha MJ. Impairment of the pituitary adrenal axis following prolonged therapy with corticotrophin. Acta Endocrinol (Copenh) 1970;65:608-16.

5 Aicardi J. Seizures and epilepsy in children under 2 years of age. In: Thyrer JH, ed. Treatment of epilepsy, Lancaster: MTP, 1980:224-30.

${ }^{6}$ Riikonen R, Donner M. ACTH therapy in infantile spasms: side effects. Arch Dis Child 1980;55:664-7.

7 Abraham GE, Manlimos FS, Garza R. Radioimmunoassay of steroids. In: Abraham GE, ed. Handbook of radioimmunoassay. New York: Marcel Dekker, 1977:591-610.

${ }^{8}$ Leisti S, Perheentupa J. Two-hour adrenocorticotrophic hormone test: accuracy in the evaluation of the hypothalamicpituitary-adrenal axis. Pediatr Res 1978:12:172-8.

9 Dixon WY. BMDP statistical software 1981. Berkeley: University of California Press, 1981.

10 Bierich JR, Eckeler E, Schönberg D. Dic prüfung der corticotropen funktion der hypophyse mit metopiron. III. Untersuchungen nach langfristiger behandlung mit ACTH. Endokrinologie 1962;42:335-41.

11 Rajmann E, Knorr D, Stocbar E, Kölle G. Bestimmung des plasmacorticols bei ACTH-behandelten kindern mit morbus still und rheumatoider arthritis. Zeitschrift fur Kinderheilkunde 1973;114:69-82.

12 Donald RA, Espiner EA. The plasma cortisol and corticotrophin response to hypoglycaemia following adrenal steroid and ACTH administration. J Clin Endocrinol Metab 1975;41: 1-6.

${ }^{13}$ Friedman M, Greenwood FC. The effects of prolonged ACTH and corticosteroid therapy in children on growth and pituitaryadrenal and pituitary function. In: James VH, Landon J, eds. The investigation of hypothalamic pituitary adrenal function. Memoirs of the Society for Endocrinology No 17. Cambridge: Cambridge University Press, 1968:249-70.

14 Bethge H. Die steroidinduzierte nebennierenunterfunktion. Pathogenese, klinik, diagnostik, prophylaxe und therapie. Klin Wochenschr 1970;48:317-32.

Correspondence to Professor J Perheentupa, Children's Hospital, SF-00290 Helsinki, Finland.

Received 8 May 1986 